Www.jmscr.igmpublication.org

Impact Factor 5.84

Index Copernicus Value: 83.27

ISSN (e)-2347-176x ISSN (p) 2455-0450

crossref DOI: _https://dx.doi.org/10.18535/jmscr/v5i7.257

Journal Of Medical Science And Clinical Research

\title{
A Rare Case of Umbilical Pilonidal Sinus Mimicking Umbilical Adenoma
}

\author{
Dr Amit Bhambri ${ }^{1}$, Dr Alok Kumar Pandey ${ }^{2}$, Dr Kanika Bhambri ${ }^{3}$ \\ ${ }^{1}$ Senior Resident Department of General Surgery AIIMS New Delhi \\ Email: bhambri0007@gmail.com, Contact details-9736868406 \\ ${ }^{2}$ Senior Resident Department of general surgery AIIMS New Delhi \\ Email: surgery1984@gmail.com, 9650073383 \\ ${ }^{3}$ Senior Resident Department of Cardiac Radiology AIIMS New Delhi \\ Email: kanikabhambri18@gmail.com, 9971210403
}

\begin{abstract}
Although most cases of pilonidal sinus are found in the sacrococcygeal region, umbilical presentations can occur as well. There are only a few reports of umbilical pilonidal sinus in the literature. We report a case of umbilical pilonidal sinus in a 22-year young male. Sinus excision was carried out and the microscopic findings revealed umbilical pilonidal sinus. The present paper recapitulates the microscopic features and treatment of this rare disease.
\end{abstract}

Keywords: Umbilical pilonidal sinus, granulation tissue, excision, young adult, recurrence.

\section{Introduction}

Pilonidal sinus disease is a common problem of the sacrococcygeal region. However, it is also observed in the periumbilical area ${ }^{1}$. Male sex, young age, hairiness, deep navel and poor personal hygiene were found to be predisposing factors $^{2}$. The predisposing factors are briefly discussed, however, the exact etiology of this disease remains unknown ${ }^{3}$. Possible mechanisms of formation are described. It is suggested that this possibility should be considered in cases of resistant or recurrent omphalitis ${ }^{4}$. Clinical as well as pathological patterns observed seem to support the hypothesis of a congenital etiopathogenesis ${ }^{5}$. Due to the risk of peritoneal extension of inflammation from this lesion, the umbilical pilonidal sinus should be treated more aggressively than its sacrococcygeal counterpart ${ }^{1}$. The importance of differential diagnosis of umbilical pilonidal sinus from other umbilical pathologies is also emphasized ${ }^{2}$. Treatment of umbilical pilonidal sinus is usually surgical ${ }^{6}$.

\section{Case Report}

A 22-year-old man presented with umbilical pain, tenderness, swelling, serosanginous discharge. Umbilical pain was the starting symptom, was followed by umbilical discharge. The discharge was serous, occasionally mixed with blood and pus. No previous history of any trauma to the umbilicus. On sinogram abdomen a linear blind ending $1.8 \mathrm{~cm}$ long subcutaneous tract is seen coursing inferiorly from external opening at umblicus (Figure 1). A $1 \mathrm{~cm}$ long branch is seen arrising from lower part of the tract coursing upwards and medially. No communication with bowel is seen. No peritoneal spillage seen. The opaque material, which was released from the 


\section{JMSCR Vol||05||Issue||07||Page 25869-25871||July}

orifice of the fistula at the umbilicus was seen through the fistula tract filling the tract. An infected pilonidal sinus was excised by wedge fashion after an umbilical abscess failed to respond to antibiotic treatment (Figure 2). Preformed defect was repaired by separate absorbable sutures from underneath. The center of new umbilicus was secured to fascia by single delayed absorbable suture. Then the skin was closed by running sub-cuticular fashion with absorbable suture. Antibiotic was administered to the patient in postop-erative period. . Histopathologic evaluation was compatible with pilonidal sinus disease. Follow-up examinations were per-formed at the first, third and sixth months after the surgery, and no recurrence was observed throughout in this period. The patient found the appearance of the new umbilicus "acceptable (figure -3).

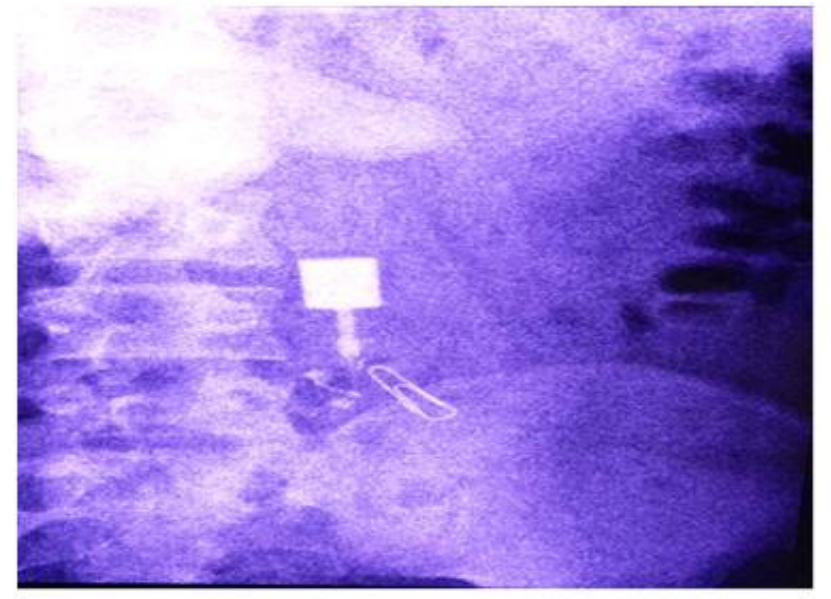

Figure 1- Abdominal Sinogram showing linear blind ending $1.8 \mathrm{~cm}$ long subcutaneous tract is seen coursing inferiorly from external opening at umblicus.

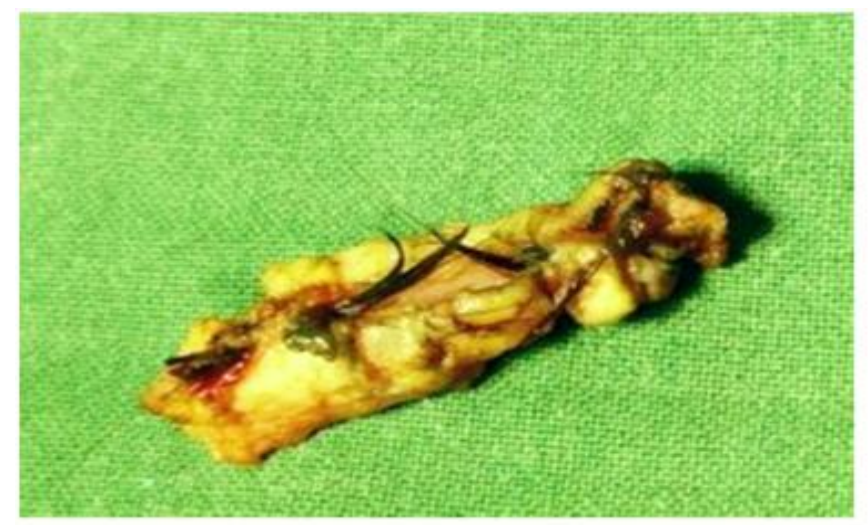

Figure 2- Excised pilonidal sinus, with tuft of hairs seen in it.

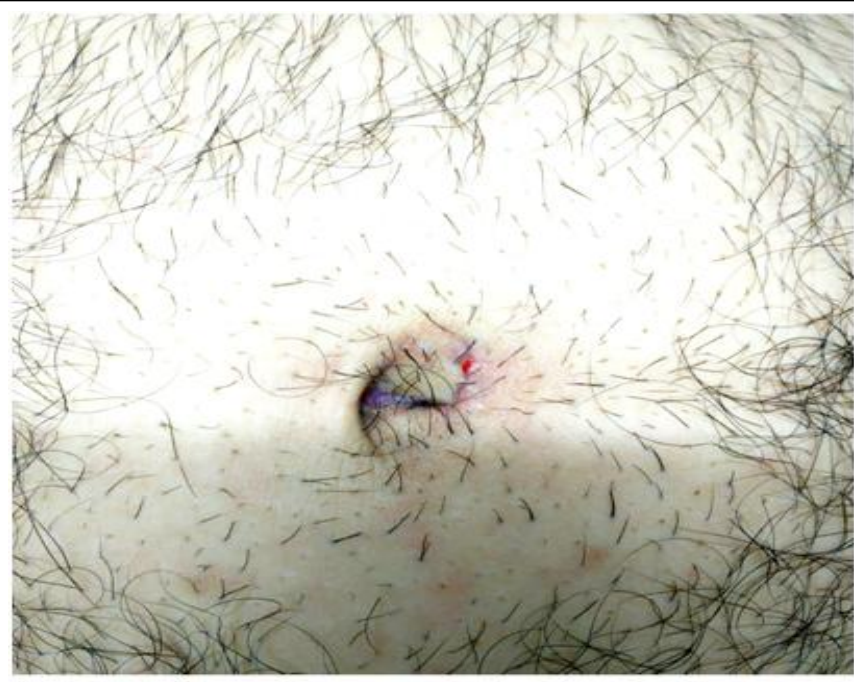

Figure 3- Wound of patient on third post-operative day healed.

\section{Discussion}

Umbilical pilonidal sinus is a rare disease compared to Sacro-coccygeal pilonidal sinus, the incidence being $0.6 \%$ as reported by Goodall in his study ${ }^{7}$.

There are many contributory factors for the development of this disease, e.g., obesity, male gender, tight clothing, deep naval, and poor personal hygeine ${ }^{8}$. There are various methods for the treatment of umbilical pilonidal sinus, ranging from simple hygienic measures, removal of hair, and keeping the umbilicus dry ${ }^{9}$ to radical excision of umbilicus. Kareem in his study ${ }^{10}$ documented a total of 134 patients were seen out of which $90.3 \%$ were men. $76.19 \%$ of patients responded to conservative treatment and rest of $23.8 \%$ were retreated by a second session of conservative treatment. Of these 25 patients, $19(76 \%)$ came back for the third visit and only three (15.78\%) patients did not respond to the treatment. Hence he concluded that conservative treatment should be regarded as the first choice and the main method of treatment in the management of umbilical pilonidal sinus ${ }^{11}$. Similarly Sarmast et al documented favourable results in over $90 \%$ of cases with conservative management ${ }^{12}$. Keeping in view good results of conservative measures, we managed our patient conservatively, and when he did not respond to conservative measures surgery with excision of umbilicus. Other differential 
diagnosis should also be kept in mind, like urachal cyst can mimic umbilical pilonidal sinus as documented by Abdulwahab et al. ${ }^{13}$

\section{References}

1. Barrett TL, Schoelch SB: Umbilical pilonidal sinus. Cutis 1998; 62: 83-84.

2. Eryilmaz R, Sahin M, Okan I et al: Umbilical pilonidal sinus disease: predisposing factors and treatment. World J Surg 2005; 29: 1158-1160.

3. Gupta S, Sikora S, Singh M, Sharma L: Pilonidal disease of the umbilicus - a report of two cases. Jpn J Surg 1990; 20: 590-592.

4. Colapinto ND: Umbilical pilonidal sinus. Br J Surg 1977; 64: 494-495.

5. Tocchi A, Liotta G, Agostini N, Maggiolini F: The umbilical pilonidal cyst: a case report. Comments on its etiopathogenesis and treatment. G Chir 1994; 15: 33-36.

6. McClenathan JH: Umbilical pilonidal sinus. Can J Surg 2000; 43: 225

7. Goodall P. The etiology and treatment of the plonidal sinus. Dig Surg 1995;12:117-20.

8. Coşkun A, Buluş H, Akıncı OF, Özgönü A. Etiological factors in umbilical pilonidal sinus. Indian J Surg 2011;73:54-7.

9. Sadeghi-Nejad H. Rains AJ. Plonidal sinus of the umbilicus. Lancet 1958;271:567-70

10. McClenathan JM. Umbilical pilonidal sinus. Can J Surg 2000;43:225-7.

11. Kareem T. Outcomes of conservative treatment of 134 cases of umbilical pilonidal sinus. World J Surg. 2013;37:313-7.

12. Sarmast MH, Javaherizadeh H, Shahvari MR. Non-surgical treatment of umblical pilonidal sins in adolescent and adult cases. Pol Przegl Chir. 2011;83:652-3

13. Abdulwahab BA, Harste K. Umbilical pilonidal sinus. Ugeskr Laeger. 2010;172(41):2848-9. 